\title{
Prevention of glomerular hyperfiltration in rats with streptozotocin-induced diabetes by an atrial natriuretic peptide receptor antagonist
}

\author{
K. Sakamoto, R. Kikkawa, M.Haneda, Y.Shigeta \\ The Third Department of Medicine, Shiga University of Medical Science, Otsu, Shiga, Japan
}

\begin{abstract}
Summary The contribution of atrial natriuretic peptide (ANP) to the development of glomerular hyperfiltration in diabetes was investigated by examining the effects of HS-142-1, a non-peptide antagonist of biological receptors for ANP, on glomerular filtration rate (GFR) and renal plasma flow (RPF) in rats with streptozotocin-induced diabetes. Three to four weeks after streptozotocin injection, the plasma concentration of ANP, urinary cyclic GMP excretion rate, GFR, and RPF were significantly higher in diabetic rats than in control rats. The increase in GFR and RPF in diabetic rats was significantly reduced, in a dose-dependent manner, by a single intravenous injection of HS-142-1; the maximal effect was apparent at a dose of $10 \mathrm{mg}$ per $\mathrm{kg}$ of body weight. Continuous
\end{abstract}

subcutaneous administration of HS-142-1 with an osmotic minipump for 3 to 4 weeks, beginning 2 days after streptozotocin injection, prevented the increases in urinary cyclic GMP excretion rate, GFR, and RPF observed in untreated diabetic rats. These results highlight the importance of ANP in the development of diabetic glomerular hyperfiltration and indicate that this condition can be prevented by continuous inhibition of the action of ANP. [Diabetologia (1995) 38: 536-542]

Key words Diabetic nephropathy, atrial natriuretic peptide, atrial natriuretic peptide receptor antagonist, glomerular hyperfiltration.
Glomerular hyperfiltration is observed in early stages of both human $[1,2]$ and experimental diabetes $[3,4]$ and has been postulated to be associated with subsequent development of diabetic nephropathy $[5,6]$. Thus, it is important to clarify the pathogenetic mechanism of glomerular hyperfiltration. Among possible mechanisms, atrial natriuretic peptide (ANP) has been suggested to mediate glomerular hyperfiltration in diabetes, because plasma ANP concentration was shown to be increased in diabetic rats with glomerular hyperfiltra-

Received: 19 July 1994 and in revised form: 22 November 1994

Corresponding author: Dr. R. Kikkawa, The Third Department of Medicine, Shiga University of Medical Science, Otsu, Shiga 520-21, Japan

Abbreviations: ANP, Atrial natriuretic peptide, GFR, glomerular filtration rate; RPF, renal plasma flow; PAH, para-aminohippurate. tion [7, 8]. Furthermore, Ortola et al. [7] demonstrated that glomerular hyperfiltration in diabetic rats was ameliorated by infusion of specific antibodies to ANP.

Recently, Morishita et al. [9] isolated a non-peptide ANP antagonist, HS-142-1, by screening a culture of Aureobasidium for ANP receptor ligands. HS-142-1 has been shown to selectively and competitively inhibit both the binding of ANP to its biological receptors and ANP-induced cyclic GMP accumulation [10-12]. Thus, HS-142-1 represents an important tool for evaluating the physiological and pathophysiological roles of ANP. We have previously shown that glomerular hyperfiltration in diabetic rats was ameliorated by a single intravenous injection of HS-142-1 (10 mg/kg body mass) [13]. We have now further examined the effects of various doses of HS-142-1 on glomerular filtration rate (GFR) and renal plasma flow (RPF) in diabetic rats. Furthermore, we investigated whether continuous subcuta- 
neous administration of HS-142-1 could prevent the development of glomerular hyperfiltration in diabetic rats.

\section{Materials and methods}

Study protocol. Diabetes was induced in male Sprague-Dawley rats (body weight, 220-260 g) by a single intravenous injection, under ether anaesthesia, of streptozotocin $(55 \mathrm{mg} / \mathrm{kg}$ body weight) dissolved in $0.1 \mathrm{~mol} / 1$ citrate buffer ( $\mathrm{pH} \mathrm{4.2)}$. Control rats received an injection of citrate buffer alone. Rats with blood glucose concentrations exceeding $16.7 \mathrm{mmol} / \mathrm{l} 2$ days after streptozotocin injection were studied as diabetic rats. Blood glucose concentrations were measured three times a week and maintained between 16.7 and $22.2 \mathrm{mmol} / \mathrm{l}$ by daily subcutaneous injection of insulin (Ultralente; Novo Industry, Copenhagen, Denmark). All rats were allowed free access to standard rat chow ( $24.8 \%$ protein by weight) and water. Three sets of experiments were performed between 3 and 4 weeks after streptozotocin injection.

In study $\mathrm{A}$, ten control rats and eleven diabetic rats were killed by decapitation and trunk blood was collected in icechilled tubes containing EDTA $(1 \mathrm{mg} / \mathrm{ml})$ and aprotinin $(1000$ kallikrein inactivator units $/ \mathrm{ml}$ ). Plasma was separated and stored at $-20^{\circ} \mathrm{C}$ for measurement of ANP.

In study B, renal clearance studies (described below) were performed in 19 control rats and 27 diabetic rats. After three baseline clearance periods, HS-142-1 (kindly supplied by Kyowa Hakko Kogyo, Tokyo, Japan) in $\mathrm{NaCl} 154 \mathrm{mmol} / \mathrm{l}$ solution was injected intravenously at a dose of $5 \mathrm{mg} / \mathrm{kg}$ (diabetic rats, $n=5$ ), $10 \mathrm{mg} / \mathrm{kg}$ (control rats, $n=8$; diabetic rats, $n=7$ ), or $20 \mathrm{mg} / \mathrm{kg}$ (control rats, $n=4$; diabetic rats, $n=5$ ). Seven control rats and 10 diabetic rats were injected with $\mathrm{NaCl}$ $154 \mathrm{mmol} / \mathrm{l}$ solution alone. Three more clearance studies were then performed. The means of the two sets of three clearance periods were taken as the baseline and experimental values, respectively.

In study C, 2 days after streptozotocin injection, an osmotic minipump (model 2ML4; Alza, Palo Alto, Calif., USA) containing $1.5 \mathrm{~g}$ of HS-142-1 in $2 \mathrm{ml}$ of $\mathrm{NaCl} 154 \mathrm{mmol} / \mathrm{l}$ solution was implanted beneath the skin of the back of six diabetic rats; HS-142-1 was infused continuously at a rate of 100 to $150 \mathrm{mg} / \mathrm{kg}$ per day. An osmotic minipump containing $\mathrm{NaCl}$ $154 \mathrm{mmol} / 1$ solution was implanted in the back of six diabetic rats and five control rats. Ten and 20 days after streptozotocin injection, blood pressure was measured by the tail-cuff method and 24-h urine samples were collected for the determination of volume, sodium, cyclic GMP. Renal clearance studies with three clearance periods were performed between 3 and 4 weeks after streptozotocin injection.

Assay of plasma ANP concentration. Plasma ANP concentration was determined by radioimmunoassay as described previously $[7,14]$. Briefly, plasma was diluted with $4 \%$ acetic acid (1:3, vol/vol), applied to a $\mathrm{C}_{18}$ Sep Pak cartridge (Waters, Milford, Mass., USA) that had been washed with $10 \mathrm{ml}$ of methanol, $5 \mathrm{ml}$ of water, and $5 \mathrm{ml}$ of $3 \%$ acetic acid. After sample application, the cartridge was washed with $5 \mathrm{ml}$ of $3 \%$ acetic acid and elution was performed with $86 \%$ ethanol in $4 \%$ acetic acid. The solvent was evaporated and the dried eluate was reconstituted with ANP assay buffer. Concentrations of ANP were then measured with an ANP radioimmunoassay kit (Amersham International, Amersham, UK). The recovery of ANP, as determined by the addition of labelled ANP to plasma, was $86.4 \pm 2.1 \%($ mean $\pm \mathrm{SD}, n=3)$. The lowest ANP con- centration that could be measured within the $95 \%$ confidence interval was $1 \mathrm{fmol} /$ tube.

Renal clearance studies. Renal clearance studies were performed as previously described [7, 13]. Rats were anaesthetized by an intraperitoneal injection of thiopental sodium $(50 \mathrm{mg} / \mathrm{kg})$ and placed on a temperature-regulated table. A catheter was inserted in the left carotid artery for blood sampling and continuous arterial blood pressure monitoring with a pressure transducer. A catheter was also inserted in the left jugular vein for infusion of inulin and para-aminohippurate (PAH) solution. The urinary bladder was catheterized for urine sampling and urine was collected into tubes of known weight. Inulin $(1 \%)$ and $\mathrm{PAH}(2.5 \%)$ in $\mathrm{NaCl} 154 \mathrm{mmol} / 1$ solution were infused at a rate of $3.6 \mathrm{ml} / \mathrm{h}$ for $20 \mathrm{~min}$ as a priming load and then infused continuously with a syringe pump at a rate of $1.2 \mathrm{ml} / \mathrm{h}$. After a 60-min equilibration period, a 30-min clearance study was performed. Blood samples $(0.25 \mathrm{ml})$ were collected at the midpoint of each clearance period for measurement of plasma inulin and PAH concentration, and the blood loss was immediately replaced by the same volume of $\mathrm{NaCl}$ $154 \mathrm{mmol} / 1$ solution. Inulin and $\mathrm{PAH}$ in plasma and urine were measured with a cysteine-tryptophan reaction [15] and a slightly modified version of the method of Brun [16], respectively. Urine samples were treated with concentrated $\mathrm{HCl}$ for 10 min at $70^{\circ} \mathrm{C}$ to hydrolyse glycated PAH [16]. Concentrations of cyclic GMP in urine were determined with a cyclic GMP RIA kit (Yamasa, Chiba, Japan). GFR was obtained from inulin clearance and RPF from $\mathrm{PAH}$ clearance.

\section{Statistical analysis}

Results are expressed as means $\pm \mathrm{SD}$. Comparisons between two groups were performed by the unpaired $t$-test. Comparisons among three or more groups were performed by oneway analysis of variance (ANOVA) followed by Scheffe's test to evaluate statistical significance between any two groups. Statistical significance was defined as a $p$ value of less than 0.05 .

\section{Results}

Study A. At the time of determination of plasma ANP concentration, the blood glucose concentration in diabetic rats was significantly higher than that in control rats (Table 1). The body mass of diabetic rats was significantly smaller than that of control rats, whereas the kidneys were significantly heavier. The amount of insulin given to diabetic rats was $2.13 \pm 0.40 \mathrm{IU} /$ day. Plasma ANP concentration was significantly higher in diabetic rats than in control rats.

Study B. The blood glucose concentration in diabetic rats $(21.5 \pm 1.8 \mathrm{mmol} / \mathrm{l})$ was significantly $(p<0.01)$ higher than that in control rats $(5.3 \pm 0.5 \mathrm{mmol} / \mathrm{l})$. Diabetic rats $(296.1 \pm 13.3 \mathrm{~g})$ were significantly $(p<0.01)$ smaller than control rats $(340.4 \pm 18.5 \mathrm{~g})$, whereas the kidneys were significantly $(p<0.01)$ heavier in diabetic rats $(2.84 \pm 0.29 \mathrm{~g})$ than in control rats $(2.37 \pm 0.31 \mathrm{~g})$. The amount of insulin given to diabetic rats was $2.25 \pm 0.55 \mathrm{IU} /$ day. GFR in the base- 
Table 1. Blood glucose concentration, body mass, kidney mass, and plasma ANP concentration 3 weeks after induction of diabetes

\begin{tabular}{lllllc}
\hline Animals & $n$ & Blood glucose $(\mathrm{mmol} / \mathrm{l})$ & Body mass $(\mathrm{g})$ & Kidney mass $(\mathrm{g})$ & Plasma ANP $(\mathrm{pg} / \mathrm{ml})$ \\
\hline Control & 10 & $6.2 \pm 0.4$ & $355.4 \pm 8.9$ & $2.48 \pm 0.08$ & $80.2 \pm 20.6$ \\
Diabetic & 11 & $19.0 \pm 1.7^{\mathrm{a}}$ & $297.1 \pm 14.1^{\mathrm{a}}$ & $2.99 \pm 0.23^{\mathrm{a}}$ & $161.2 \pm 33.7^{\mathrm{a}}$ \\
\hline
\end{tabular}

Values are means $\pm \mathrm{SD}$.

${ }^{a} p<0.01$ vs control

Table 2. Effect of intravenous injection of HS-142-1 on urinary cyclic GMP excretion rate in moderately hyperglycaemic rats 34 weeks after induction of diabetes

\begin{tabular}{|c|c|c|c|c|}
\hline \multirow[t]{3}{*}{ HS-142-1 (mg/kg) } & \multicolumn{4}{|c|}{ Urinary cyclic GMP excretion rate (pmol/min) } \\
\hline & \multicolumn{2}{|l|}{ Control } & \multicolumn{2}{|l|}{ Diabetic } \\
\hline & Baseline & Experimental & Baseline & Experimental \\
\hline 0 & $30.2 \pm 5.6$ & $29.5 \pm 5.1$ & $45.9 \pm 13.4$ & $\begin{array}{l}45.4 \pm 8.6 \\
326+72\end{array}$ \\
\hline $\begin{array}{r}5 \\
10\end{array}$ & $30.6 \pm 5.1$ & $19.3 \pm 3.4^{\mathrm{a}}$ & $\begin{array}{l}43.5 \pm 7.7 \\
49.1 \pm 12.7\end{array}$ & $\begin{array}{l}32.6 \pm 7.2 \\
30.3 \pm 3.2^{\mathrm{a}}\end{array}$ \\
\hline 20 & $24.6 \pm 1.5$ & $11.1 \pm 1.0^{\mathrm{a}}$ & $39.7 \pm 8.5$ & $24.4 \pm 6.8^{\mathrm{a}}$ \\
\hline
\end{tabular}

Values are means \pm SD.

${ }^{a} p<0.01$ vs baseline of the same group

Table 3. Effect of continuous infusion of HS-142-1 on blood glucose concentration, body mass, and systolic blood pressure of diabetic rats

\begin{tabular}{lllll}
\hline Animals & $n$ & Blood glucose $(\mathrm{mmol} / \mathrm{l})$ & Body mass $(\mathrm{g})$ & Blood pressure $(\mathrm{mm} \mathrm{Hg})$ \\
\hline Control & & & Day 10 & \\
Diabetic & 5 & $5.7 \pm 0.8$ & $286.8 \pm 8.8$ & $112.4 \pm 8.6$ \\
Diabetic + HS-142-1 & 6 & $21.5 \pm 3.6^{\mathrm{a}}$ & $233.0 \pm 13.4^{\mathrm{a}}$ & $115.1 \pm 9.9$ \\
& 6 & $21.2 \pm 3.3^{\mathrm{a}}$ & $232.8 \pm 13.9^{\mathrm{a}}$ & $122.0 \pm 4.3$ \\
Control & 5 & $5.7 \pm 0.8$ & Day 20 & \\
Diabetic & 6 & $21.8 \pm 1.3^{\mathrm{a}}$ & $341.8 \pm 18.2$ & $116.8 \pm 4.8$ \\
Diabetic + HS-142-1 & 6 & $20.5 \pm 2.2^{\mathrm{a}}$ & $292.1 \pm 15.9^{\mathrm{a}}$ & $120.0 \pm 11.3$ \\
\hline
\end{tabular}

Values are means \pm SD.

${ }^{a} p<0.01$ vs control of the same day

line period was significantly $(p<0.01)$ higher in diabetic rats $(4.28 \pm 0.30 \mathrm{ml} / \mathrm{min})$ than in control rats $(3.19 \pm 0.49 \mathrm{ml} / \mathrm{min})$, as was the RPF $(11.37 \pm 1.62 \mathrm{vs}$ $9.63 \pm 1.47 \mathrm{ml} / \mathrm{min}$, respectively; $p<0.01$ ). Urinary cyclic GMP excretion rate in the baseline period was significantly $(p<0.01)$ higher in diabetic rats $(45.1 \pm 11.9 \mathrm{pmol} / \mathrm{min})$ than in control rats (29.2 $\pm 5.4 \mathrm{pmol} / \mathrm{min})$. Injection of HS-142-1 resulted in a decrease in GFR in diabetic rats (Fig.1B) but had no effect of on GFR in control rats (Fig.1A). The effect of HS-142-1 was dose-dependent; the maximal effect, reduction of GFR to control values, was apparent at a dose of $10 \mathrm{mg} / \mathrm{kg}$ (Fig. 1C). HS-142-1 similarly suppressed the increased RPF in diabetic rats in a dose-dependent fashion (Fig. 2, B and C), without affecting RPF in control rats (Fig. 2A). Urinary cyclic GMP excretion rate in both control and diabetic rats decreased in a dose-dependent manner after injection of HS-142-1 (Table 2). Mean arterial pressure in the baseline period did not differ between diabetic and control rats $(122.1 \pm 11.9$ vs $125.4 \pm 4.9 \mathrm{~mm} \mathrm{Hg}$, respectively), and it remained un- changed in diabetic rats after injection of HS-142-1 $(127.9 \pm 7.0, \quad 124.0 \pm 9.5$, and $123.2 \pm 19.2 \mathrm{~mm} \mathrm{Hg}$ after injection of vehicle or HS-142-1 at 10 or $20 \mathrm{mg} /$ $\mathrm{kg}$, respectively).

Study C. Blood glucose concentrations in diabetic rats treated or not treated with HS-142-1 were within the range of moderate hyperglycaemia, and the body mass of diabetic rats was significantly smaller than that of control rats (Table 3 ). Continuous infusion of HS-142-1 did not affect body mass. The amount of insulin given was not different between HS-142-1-treated and untreated diabetic rats $(2.30 \pm 0.49$ vs $2.48 \pm 0.22 \mathrm{IU} /$ day, respectively). Systolic blood pressure did not differ among control rats, untreated diabetic rats, or diabetic rats treated with HS-142-1. Urinary volume (Fig. $3 \mathrm{~A}$ ) and sodium excretion rate (Fig. 3 B) in 24-h urine samples on day 10 and 20 were significantly higher for diabetic rats than for control rats; HS-142-1 did not affect either parameter in diabetic rats. Urinary cyclic GMP excretion rates in 24-h urine samples on day 10 and 20 were 
A

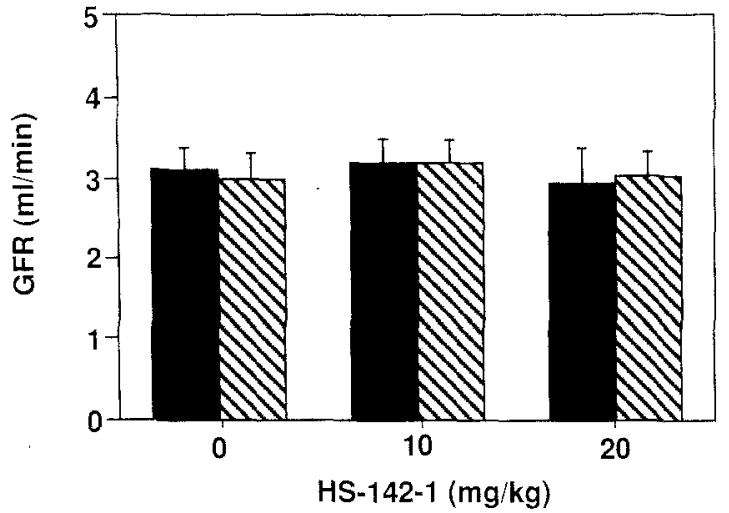

B

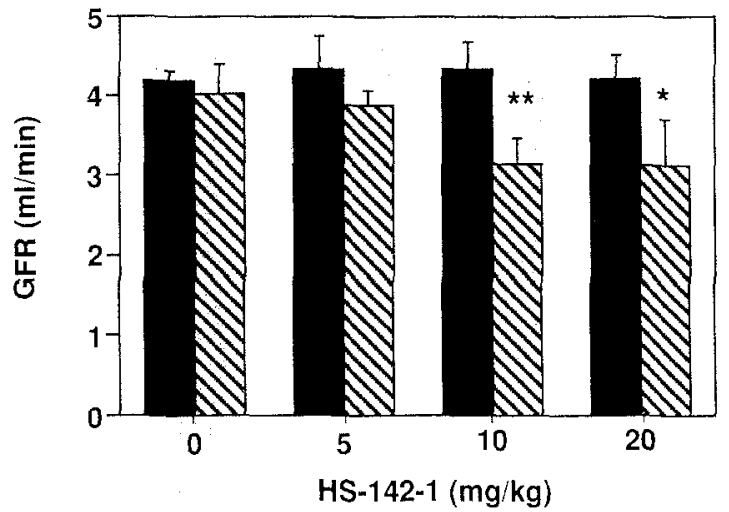

C

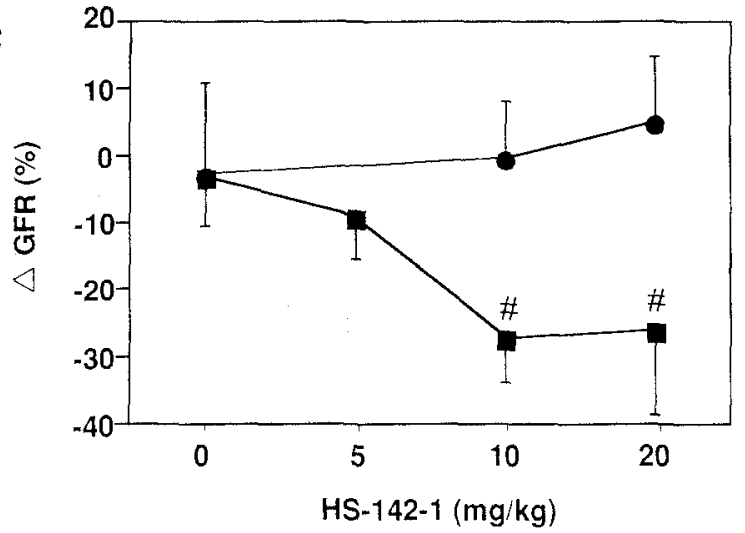

Fig.1. (A-C) Effect of intravenous injection of HS-142-1 on GFR. Control rats (A) and diabetic rats (B) were injected with vehicle (seven control rats, ten diabetic rats) or HS-142-1 at $5 \mathrm{mg} / \mathrm{kg}$ (five diabetic rats), $10 \mathrm{mg} / \mathrm{kg}$ (eight control rats, seven diabetic rats), or $20 \mathrm{mg} / \mathrm{kg}$ (four control rats, five diabetic rats). GFR was measured in both baseline ( $\boldsymbol{(}$ ) and experimental (N) periods. (C) Percent changes in GFR in control rats $(\bullet)$ and diabetic rats $(\boldsymbol{\square})$. Values are means \pm SD. $* p<0.05$; ** $p<0.01$ vs baseline; $\# p<0.01$ vs vehicle

also significantly higher for diabetic rats than for control rats (Fig. 3C); continuous infusion with HS-142-1 prevented the increase in urinary cyclic GMP excretion rate in diabetic rats. Kidney mass was significantly $(p<0.05)$ greater in untreated diabetic rats $(2.65 \pm 0.07 \mathrm{~g})$ than in control rats $(2.37 \pm 0.13 \mathrm{~g})$; HS-142-1 did not affect kidney mass $(2.82 \pm 0.20 \mathrm{~g})$. The GFR was significantly higher in untreated diabetic rats than in control rats, but HS-142-1 prevent-
A

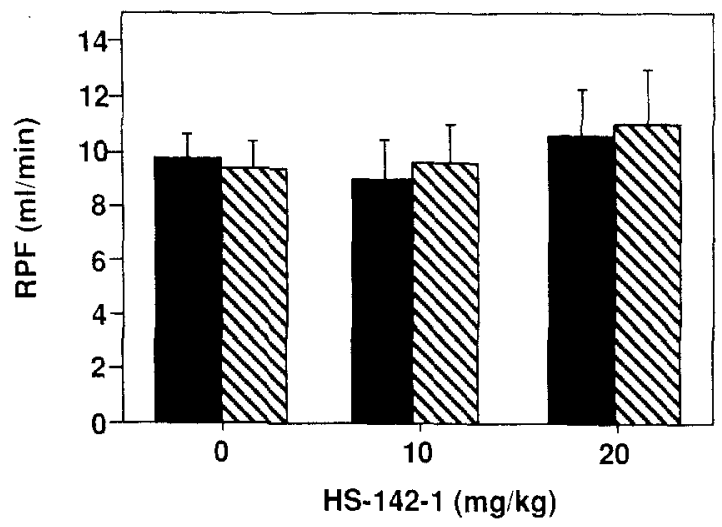

B
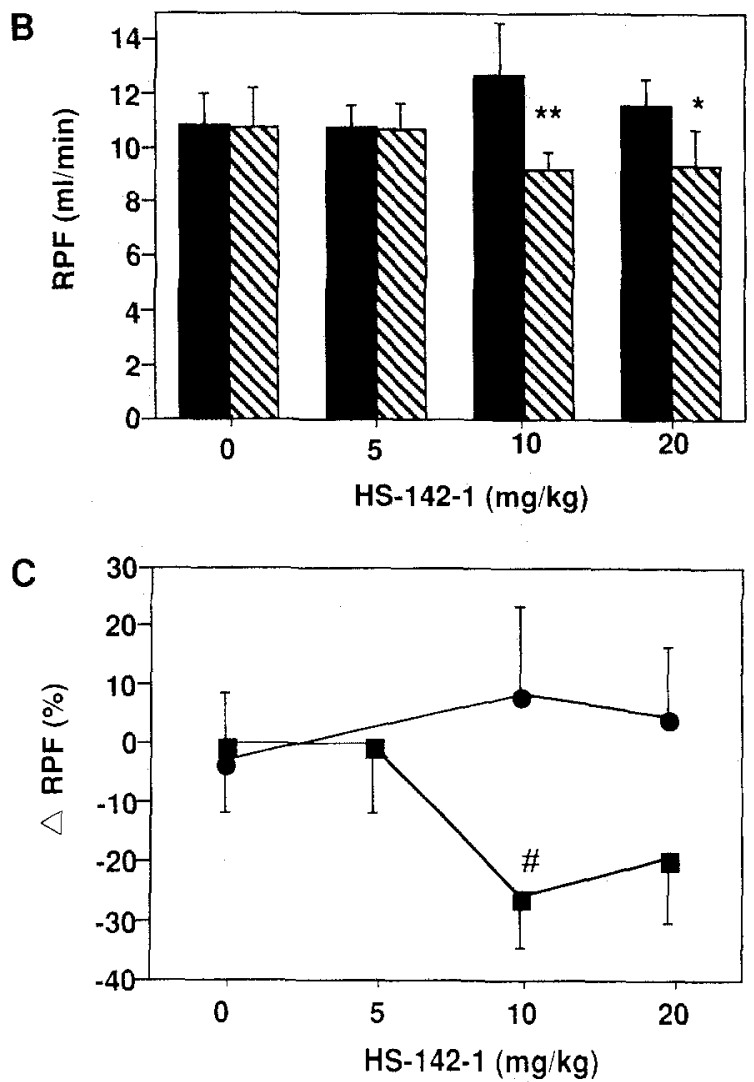

Fig. 2. (A-C) Effect of intravenous injection of HS-142-1 on RPF. Control rats (A) and diabetic rats $(\mathbf{B})$ were injected with vehicle or HS-142-1 as described in the legend to Fig. 1. RPF was measured in both baseline ( $\mathbf{(})$ and experimental (N) periods. (C) Percent changes in RPF in control rats $(\bullet)$ and diabetic rats $(\mathbf{\square})$. Values are means $\pm \mathrm{SD}$. $* p<0.05 ; * * p<0.01$ vs baseline; \# $p<0.01$ vs vehicle

ed the increase in GFR in diabetic rats (Fig. 4A). Similarly, HS-142-1 prevented an increase in RPF in diabetic rats (Fig. 4B). Urinary cyclic GMP excretion rate during renal clearance in untreated diabetic rats was significantly higher than that in control rats and in diabetic rats treated with HS-142-1 (Fig. 4 C). At the end of renal clearance study, the blood glucose concentration in HS-142-1-treated or untreated diabetic rats $(21.0 \pm 4.8,19.9 \pm 2.7 \mathrm{mmol} / \mathrm{l}$, respectively) were significantly $(p<0.01)$ higher than in control rats $(8.2 \pm 1.9 \mathrm{mmol} / \mathrm{l})$. 


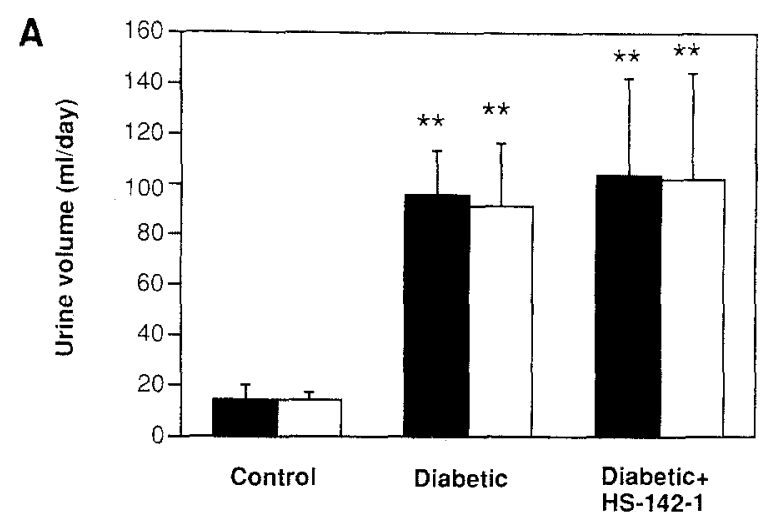

B

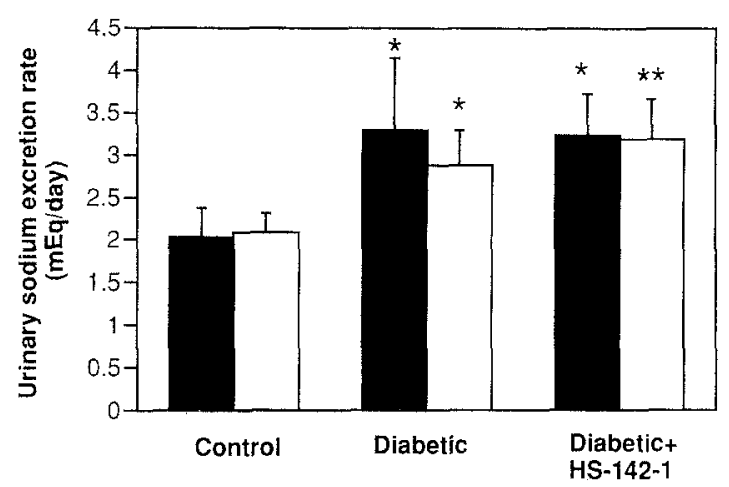

C

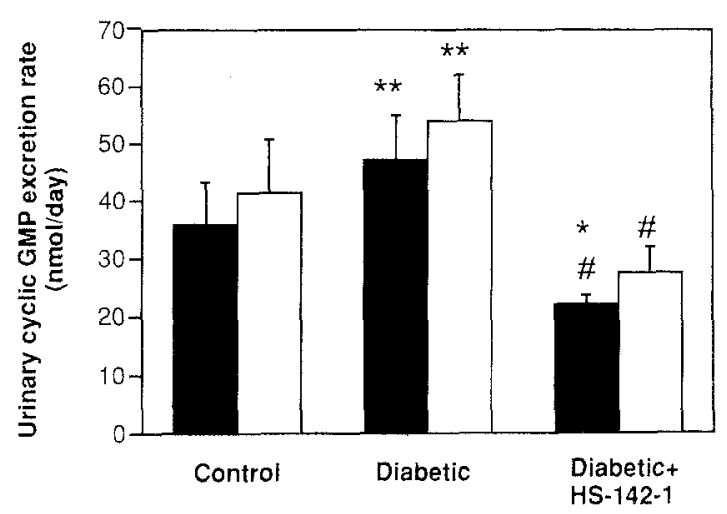

Fig.3. (A-C) Urine volume (A), urinary sodium excretion rate (B), urinary cyclic GMP excretion rate $(\mathbf{C})$ in control rats $(n=5)$, untreated diabetic rats $(n=6)$, and diabetic rats treated with HS-142-1 $(n=6)$ for 10 days (ם) and 20 days $(\square)$ after induction of diabetes. Values are means \pm SD. $* p<0.05$; ** $p<0.01$ vs control rats; \# $p<0.01$ vs untreated diabetic rats

\section{Discussion}

We have confirmed that the plasma ANP concentration is increased in diabetic rats with glomerular hyperfiltration, and we have shown that glomerular hyperfiltration in diabetic rats can be normalized by an intravenous injection of an ANP receptor antagonist and prevented by a continuous inhibition of ANP action.

Our observations of an increase in plasma ANP and an increase in urinary cyclic GMP excretion rate which is a biological marker for the renal activity of ANP in vivo $[17,18]$ in diabetic rats with moderate
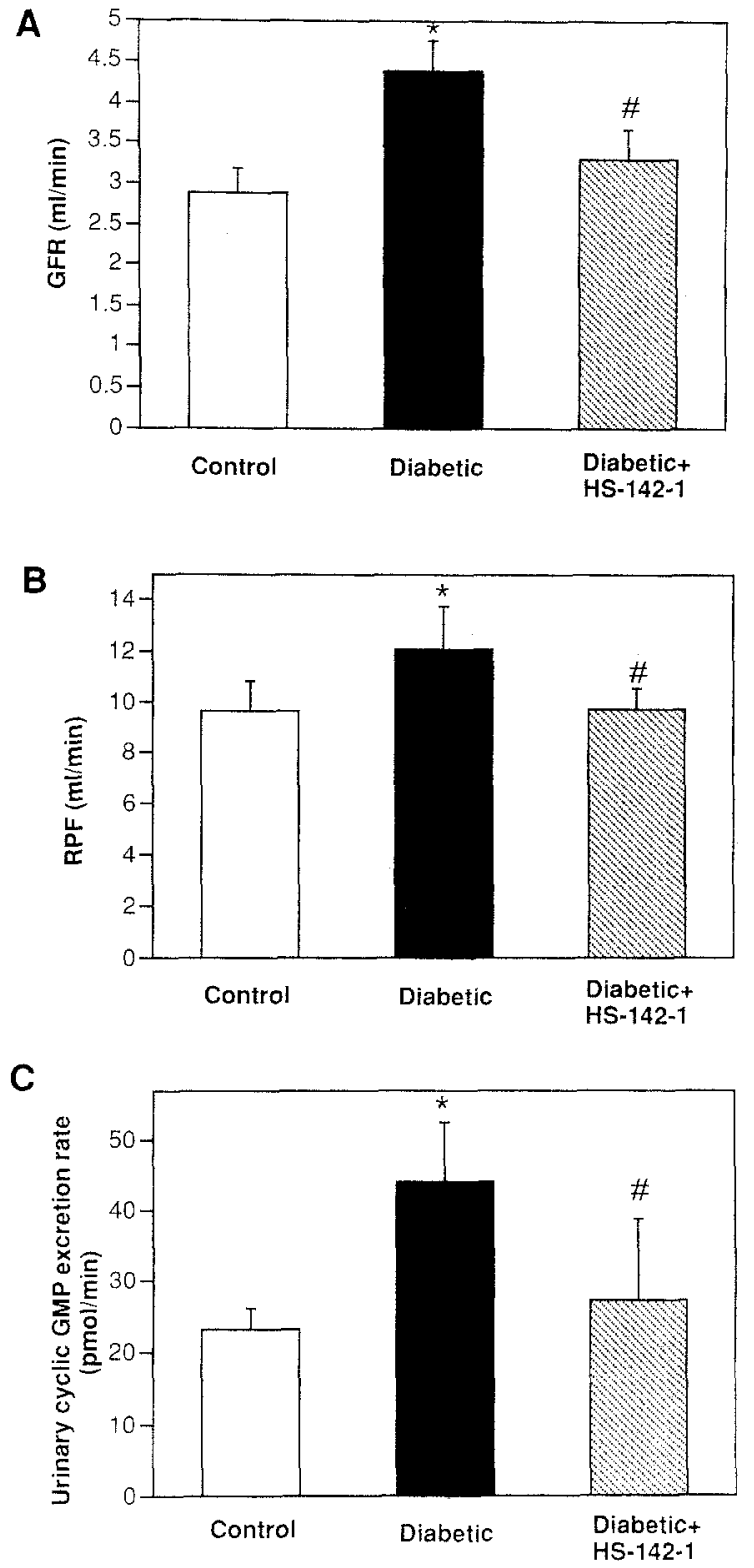

Fig. 4. (A-C) GFR (A), RPF (B), urinary cyclic GMP excretion rate $(\mathbf{C})$ during the clearance period in control rats $(n=5)$, untreated diabetic rats $(n=6)$, and diabetic rats treated with HS-142-1 $(n=6)$. Values are means \pm SD. $* p<0.01$ vs control rats; $\# p<0.01$ vs untreated diabetic rats

hyperglycaemia are consistent with the results of previous studies $[7,8,19,20]$. Plasma ANP concentration in diabetic rats has been shown to be increased 2 weeks [7], 6 weeks [19], 8 weeks [8], or 12 weeks after the onset of diabetes [12]. These data suggest that ANP action may be enhanced from the early stage of diabetes and for a substantial period, and they raise the possibility that the increase in plasma ANP affects renal haemodynamics. However, Okwueze et al. [21] reported that in spontaneous diabetes-prone (BB/DP) rats, no elevation of ANP was found and treatment with ANP receptor antagonist had no impact on glomerular hyperfiltration. The rea- 
son for this difference is unclear; it might relate to differences in the rat strain, the duration of diabetes, glycaemic control, insulin dose and ANP receptor antagonist. In human diabetic patients, the relationship between plasma ANP concentration and glomerular hyperfiltration is controversial. Sawicki et al. [22] reported that plasma ANP concentrations in diabetic patients with hyperfiltration were higher than those in diabetic patients with normal GFR and in normal subjects. Bell et al. [23] reported that plasma ANP concentration was elevated in diabetic patients with poor glycaemic control compared with diabetic patients with moderate glycaemic control and in normal subjects. On the other hand, Predel et al. [24] and Smits et al. [25] reported that baseline levels of ANP were not different between diabetic patients and control subjects, though in the former report, baseline levels of GFR in diabetic patients were not higher than in control subjects and GFR values were not investigated in the latter report.

Two types of ANP receptors, biological receptors and clearance receptors [26], have been identified. HS-142-1 is an antagonist for ANP biological receptors and selectively inhibits ANP-induced cyclic GMP generation in vitro $[11,12]$. HS-142-1 also inhibits diuresis and urinary cyclic GMP excretion induced by acute volume expansion [27] or by an infusion of ANP [28] in rats in vivo. Thus, HS-142-1 represents a tool with which to examine the role of ANP in glomerular hyperfiltration in diabetes. We have previously shown that glomerular hyperfiltration in diabetic rats is ameliorated by a single intravenous injection of HS-142-1 (10 mg/kg body weight) [13].

In the present study, we examined the effects of various amounts of HS-142-1 on GFR and RPF in diabetic rats. The increased GFR and RPF in diabetic rats were reduced in a dose-dependent manner by HS-142-1, as was the urinary cyclic GMP excretion rate. The maximal effect of HS-142-1 was apparent at a dose of $10 \mathrm{mg} / \mathrm{kg}$. These data are consistent with those of Ortola et al. [7] showing that glomerular hyperfiltration in diabetic rats was ameliorated by infusion of specific antibodies to ANP, and they indicate that the dilation of pre-glomerular arterioles by ANP induces renal hyperperfusion and glomerular hyperfiltration. GFR and RPF in control rats remained unchanged after an injection of HS-142-1, despite a decline in urinary cyclic GMP excretion. Antiserum to ANP was shown to have no effect on GFR either in rats with congestive heart failure, a normal GFR, and a high ANP concentration, or in control rats [29]. Therefore, it is not surprising that GFR and RPF in control rats remained unchanged after an injection of HS-142-1. This finding may indicate that, in control rats, ANP does not contribute to the maintenance of baseline renal haemodynamics, or that other hormonal or neuronal factors may compensate for the inhibition of ANP action.
To examine whether continuous inhibition of ANP action could prevent the development of glomerular hyperfiltration in diabetic rats, we continuously administered HS-142-1 with the use of an osmotic minipump. HS-142-1 was administered subcutaneously at a dose of $100-150 \mathrm{mg} / \mathrm{kg}$ per day, which was 10 to 15 times higher than the maximally effective dose administered by intravenous injection. This dose was found to be effective because it prevented the increase in urinary cyclic GMP excretion rate apparent in untreated diabetic rats. The increases in both GFR and RPF in diabetic rats were also prevented by continuous administration of HS-142-1. Thus, continuous inhibition of the action of ANP prevented renal hyperperfusion and glomerular hyperfiltration in diabetic rats.

Urinary sodium excretion rate in 24-h urine samples was significantly higher in diabetic rats than in control rats. This result is consistent with those of previous studies [30,31], in which increased urinary sodium excretion in diabetic rats was thought to result from increased sodium intake (attributable to hyperphagia), osmotic diuresis (attributable to hyperglycaemia), and glomerular hyperfiltration. Although continuous infusion of HS-142-1 prevented glomerular hyperfiltration, urinary sodium excretion rate was not affected, suggesting that other mechanisms are responsible for maintaining the increased urinary sodium excretion in diabetic rats treated with HS-1421. Further studies are needed to clarify the effect of ANP on sodium balance in diabetic rats.

In conclusion, we have shown that glomerular hyperfiltration in diabetic rats can be normalized by intravenous injection of an ANP receptor antagonist and prevented by continuous inhibition on ANP action. Because glomerular hyperfiltration appears to be related to the development of diabetic nephropathy in both humans [5] and animals [6,32] with diabetes, HS-142-1 may prove a useful tool in determining whether the long-term normalization of glomerular hyperfiltration may be useful in preventing diabetic nephropathy.

Acknowledgements. We thank Dr. Y. Matsuda (Kyowa Hakko Kogyo, Tokyo, Japan) for the gift of HS-142-1, and Drs. D. Koya, T. Uzu, and T.Shikano (Shiga University of Medical Science, Shiga, Japan) for helpful suggestions in performing this study.

\section{References}

1. Mogensen CE, Andersen MJF (1975) Increased kidney size and glomerular filtration rate in untreated juvenile diabetes: normalization by insulin-treatment. Diabetologia 11: 221-224

2. Christiansen JS, Gammelgaard J, Frandsen M, Parving $\mathbf{H}$ H (1981) Increased kidney size, glomerular filtration rate and renal plasma flow in short-term insulin-dependent diabetics. Diabetologia 20: 451-456 
3. Hostetter TH, Troy JL, Brenner BM (1981) Glomerular hemodynamics in experimental diabetes mellitus. Kidney Int 19: 410-415

4. Jensen PK, Christiansen JS, Steven K, Parving H-H (1981) Renal function in streptozotocin-diabetic rats. Diabetologia 21: 409-414

5. Mogensen CE, Christensen CK (1984) Predicting diabetic nephropathy in insulin-dependent patients. N Engl J Med 311: 89-93

6. Hostetter TH, Rennke HG, Brenner BM (1982) The case for intrarenal hypertension in the initiation and progression of diabetic and other glomerulopathies. Am J Med 72: 375-380

7. Ortola FV, Ballermann BJ, Anderson S, Mendez RE, Brenner BM (1987) Elevated plasma atrial natriuretic peptide levels in diabetic rats. Potential mediator of hyperfiltration. J Clin Invest 80: 670-674

8. Perico N, Benigni A, Gabanelli M et al. (1992) Atrial natriuretic peptide and prostacyclin synergistically mediate hyperfiltration and hyperperfusion of diabetic rats. Diabetes 41: 533-538

9. Morishita Y, Takahashi M, Sano T et al. (1991) Isolation and purification of HS-142-1, a novel nonpeptide antagonist for the atrial natriuretic peptide receptor, from Aureobasidium sp. Agric Biol Chem 55: 3017-3025

10. Morishita Y, Sano T, Kase H, Yamada K, Inagami T, Matsuda Y (1992) HS-142-1, a novel nonpeptide atrial natriuretic peptide (ANP) antagonist, blocks ANP-induced renal responses through a specific interaction with guanylyl cyclase-linked receptors. Eur J Pharmacol 225: 203-207

11. Tanaka T, Ichimura M, Nakajo S et al. (1992) HS-142-1, a novel non-peptide antagonist for atrial natriuretic peptide receptor, selectively inhibits particulate guanylyl cyclase and lowers cyclic GMP in LLC-PK 1 cells. Biosci Biotech Biochem 56: 1041-1045

12. Haneda M, Kikkawa R, Koyo D et al. (1993) Biological receptors mediate anti-proliferative action of atrial natriuretic peptide in cultured mesangial cells. Biochem. Biophys Res Commun 192: 642-648

13. Kikkawa R, Haneda M, Sakamoto K et al. (1993) Antagonist for atrial natriuretic peptide receptors ameliorates glomerular hyperfiltration in diabetic rats. Biochem Biophys Res Commun 193: 700-705

14. Lang RE, Tholken H, Ganten D, Luft FC, Ruskoaho H, Unger T (1985) Atrial natriuretic factor - a circulating hormone stimulated by volume loading. Nature 314: 264-266

15. Waugh WH (1977) Photometry of inulin and polyfructosan by use of a cysteine/tryptophan reaction. Clin Chem 23: 639-645

16. Dalton RN, Wiseman MJ, Turner C, Viberti G (1988) Measurement of urinary para-aminohippuric acid in glycosuric diabetics. Kidney Int 34: 117-120

17. Wong KR, Xie M-H, Shi L-B et al. (1988) Urinary cGMP as biological marker of the renal activity of atrial natriuretic factor. Am J Physiol 255: F1220-F1224
18. Huang C-L, Ives HE, Cogan MG (1986) In vivo evidence that cGMP is the second messenger for atrial natriuretic factor. Proc Natl Acad Sci USA 83: 8015-8018

19. Hebden RA, Todd ME, McNeill JH (1989) Relationship between atrial granularity and release of atrial natriuretic factor in rats with diabetes mellitus. Am J Physiol 257: R932-R938

20. Todd ME, Hebden RA, Gowen B, Tang C, McNeill JH (1990) Atrial structure and plasma ANF levels in rats with chronic diabetes mellitus. Diabetes 39: 483-489

21. Okwueze MI, Opgenorth TJ, Geldern TWV, Vari RC (1994) Atrial natriuretic peptide and glomerular hyperfiltration during onset of spontaneous diabetes mellitus. Am J Physiol 266: R572-R577

22. Sawicki PT, Heinemann L, Rave K, Hohmann A, Berger M (1988) Atrial natriuretic factor in various stages of diabetic nephropathy. J Diabetic Complications 2: 207-209

23. Bell GM, Bernstein RK, Laragh JH, Atlas SA, James GD, Pecker MS et al. (1989) Increased plasma atrial natriuretic factor and reduced plasma renin in patients with poorly controlled diabetes mellitus. Clin Sci 77: 177-182

24. Predel HG, Schulte-Vels O, Sorger M, Glanzer K, Geller C, Kramer HJ (1990) Atrial natriuretic peptide in patients with diabetes mellitus type I. Am J Hypertens 3: 674-681

25. Smits P, Hersbach FMRJ, Jansen TLTA, Thien T, Lutterman JA (1993) Impaired vasodilator response to atrial natriuretic factor in IDDM. Diabetes 42: 1454-1461

26. Maack T (1992) Receptors of atrial natriuretic factor. Annu Rev Physiol 54: 11-27

27. Sano T, Morishita Y, Yamada K, Matsuda Y (1992) Effects of HS-142-1, a novel non-peptide ANP antagonist, on diuresis and natriuresis induced by acute volume expansion in anesthetized rats. Biochem Biophys Res Commun 182: 824-829

28. Sano T, Morishita Y, Matsuda Y, Yamada K (1992) Pharmacological profile of HS-142-1, a novel nonpeptide atrial natriuretic peptide antagonist of microbial origin. I. Selective inhibition of the actions of natriuretic peptides in anesthetized rats. J Pharmacol Exp Ther 260: 825-831

29. Awazu M, Imada T, Kon V, Inagami T, Ichikawa I (1989) Role of endogenous atrial natriuretic peptide in congestive heart failure. Am J Physiol 257: R641-R646

30. Christlieb AR, Long R, Underwood RH (1979) Reninangiotensin-aldosterone system, electrolyte homeostasis and blood pressure in alloxan diabetes. Am J Med Sci 277: $295-303$

31. Hebden RA, Gardiner SM, Bennett T, MacDonald IA (1986) The influence of streptozotocin-induced diabetes mellitus on fluid and electrolyte handling in rats. Clin Sci 70: $111-117$

32. Zatz R, Meyer TW, Rennke HG, Brenner BM (1985) Predominance of hemodynamic rather than metabolic factors in the pathogenesis of diabetic glomerulopathy. Proc Natl Acad Sci USA 82: 5963-5967 